Portland State University

PDXScholar

\title{
Carbon Dioxide Concentrations: An Examination of Carbon Sequestration via Global Reforestation
}

Jordan Bertagnolli

Portland State University

Follow this and additional works at: https://pdxscholar.library.pdx.edu/honorstheses

Let us know how access to this document benefits you.

\section{Recommended Citation}

Bertagnolli, Jordan, "Carbon Dioxide Concentrations: An Examination of Carbon Sequestration via Global Reforestation" (2016). University Honors Theses. Paper 275.

https://doi.org/10.15760/honors.295

This Thesis is brought to you for free and open access. It has been accepted for inclusion in University Honors Theses by an authorized administrator of PDXScholar. Please contact us if we can make this document more accessible: pdxscholar@pdx.edu. 
Carbon Dioxide Concentrations: An Examination of Carbon Sequestration via Global Reforestation.

by

Jordan Bertagnolli

An undergraduate honors thesis submitted in partial fulfillment of the

Requirements for the degree of

Bachelor of Science

in

University Honors

and

Environmental Science

Thesis Advisor

Professor Patrick Emerson 


\section{Table of Contents}

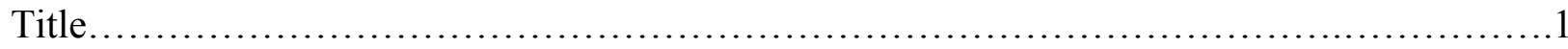

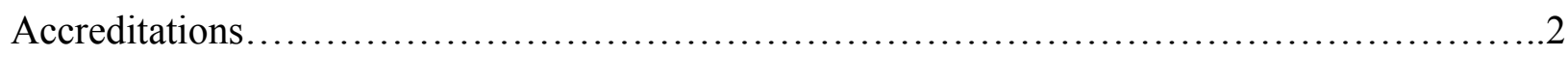

Table of Contents...................................................................

Abstract....................................................................

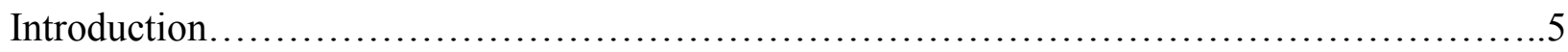

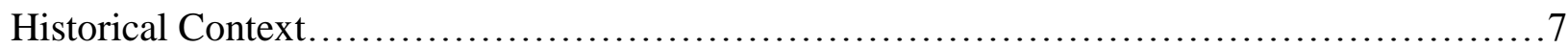

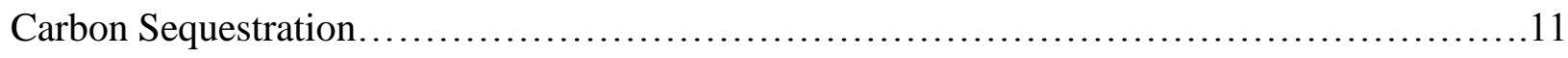

Scientific and Historical Evidence................................................. 14

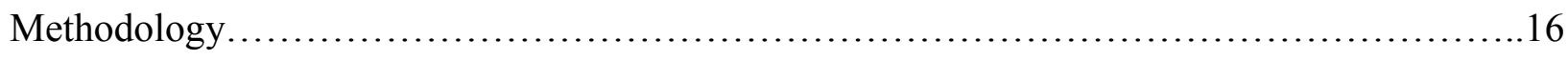

Results......................................................................... 17

Discussion.................................................................... 19

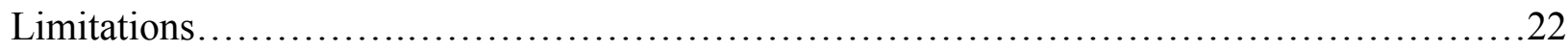

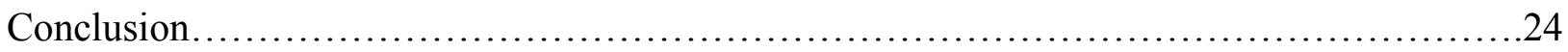

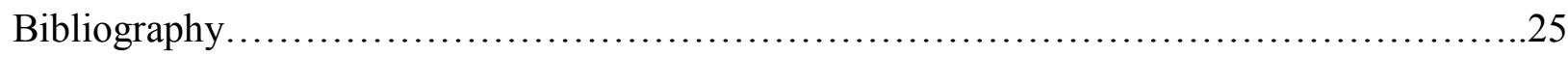




\begin{abstract}
Deforestation has resulted in a dramatic change to Earth's landscape, climate, and ecosystems. To date, $46 \%$ of all forests have been cut since the onset of agriculture about 12,000 years ago (Crowther et al., 2015). During that same time, greenhouse gas concentrations have grown by $51.8 \%$ (Crowther et al., 2015). A solution to this problem could be vast carbon capture initiatives involving tree planting. Historical reforestation efforts have thus far been conducted regionally and currently make up less than $1 \%$ of the forest cover that they are replacing. With current $\mathrm{CO}_{2}$ concentrations at a record high of 402.26 ppm (NOAA, 2016), the question that I sought to answer was; could reforestation alone reduce $\mathrm{CO}_{2}$ concentrations to pre-industrial levels? The purpose of this paper is to answer this academic question in a manner that is objective and constructive. Calculating total available land for reforestation with average temperate and tropical carbon sequestration rates reveals the potential for a $2 \%$ annual uptake in global $\mathrm{CO}_{2}$ sequestration (Brown et al., 1996). This increase would translate into a projected $2050 \mathrm{CO}_{2}$ concentration of 361.22-373.96 parts per million (ppm). This reduction, although significant, would only represent a $7.57-11.36 \%$ reduction: far short of the $51.8 \%$ reduction necessary to bring $\mathrm{CO}_{2}$ concentrations back to preindustrial levels.
\end{abstract}




\section{Introduction}

In this paper, I will examine whether reforestation alone could reduce $\mathrm{CO}_{2}$ concentrations to pre-industrial levels. Although the question is complex, I have chosen to pursue it in order to better understand the role that forests play in climate change and greenhouse gas mitigation. To answer this question, I will proceed through a number of steps. I will first identify the necessary scientific evidence available and the reason for using such evidence when studying climatology. Second, I will establish the critical role that forests play in the global carbon cycle. Third, I will give historical context for the rise in atmospheric $\mathrm{CO}_{2}$ concentrations, starting with the preindustrial $\mathrm{CO}_{2}$ baseline of 1750 and ending with the most recent $\mathrm{CO}_{2}$ count taken by the National Oceanic and Atmospheric Administration. Fourth, I will provide sources from satellite tree counts that demonstrate the potential lands for reforestation globally, and then I will calculate the equivalent $\mathrm{CO}_{2}$ removed from the atmosphere if all of those available lands were reforested.

Lastly, I will compare the potential $\mathrm{CO}_{2}$ reductions under such a global reforestation campaign to the pre-industrial $\mathrm{CO}_{2}$ level of 1750. I have separated the sections of this paper by topic, and I have defined all scientific terms so as to make this document accessible to any audience.

This paper proceeds as follows: first, I will investigate the historical context regarding forests. I will probe the threats to forests globally and offer a rationale for why their protection is beneficial to the planet and the future of humanity. Second, I will review the carbon cycle; identifying both carbon sequestration and why carbon dioxide is the common metric for greenhouse gas emissions. Additionally, I will cover the related topics of new forest regeneration rates and the possibility for positive and negative feedback loops. Third, I will analyze the availability of scientific and historical evidence to support my findings. I will emphasize ice cores as the critical information source for past climatological data. Fourth, I will illustrate my 
methods, citing the primary sources from which my findings originated. The purpose of this section is for future scholars to repeat my steps using the same information. Fifth, I will present the results, summarized for textual presentation. Sixth, I will discuss the significance of my findings, beginning with the historical lack of interest in using reforestation as a tool. I will transition into the true availability of reforest-able land, and global sequestration potential. Seventh, I will conclude with a reiteration of the research question and my findings. I leave the reader with an answer to the question and a realistic outlook on possible solutions. Lastly, I will provide a literature meta-analysis to further explore the patterns stereotypical of the available literature, including biases of the sources, the authors' fields of study, and common sources of evidence. 


\section{Historical Context}

In this section, I will examine the idea of humans as the dominant force on the planet. Using evidence of changes to the natural landscape, I will demonstrate that we have entered a new geologic era. Forests are emblematic of the system-wide health of an ecological region and the planet as a whole. To use a suitable analogy, our remaining forests may well be the canary in the coal mine for events to come. To emphasize the importance of my research question, I will provide evidence for the current state of our forests and the methods by which they are threatened.

Human influenced changes to the carbon cycle, along with our systemic over-exploitation of the Earth's natural resources, have led those in the field of geology and the natural sciences to coin the phrase 'anthropocene'. Popularized by author Paul Crutzen, the Anthropocene is understood by many to refer to our current geologic era, viewed as the period during which human activity has been the dominant influence on climate and the environment (Smithsonian, 2013). Many current human activities are stereotypical of the Anthropocene, such as sprawling cities, dams, and irrigation systems, but few leave such long lasting effects on the environment as deforestation. Forests are the dominant terrestrial ecosystem on Earth and are distributed across the globe (Falkner, 2013). Forests account for approximately $75 \%$ of the gross primary productivity of Earth's biosphere (Breuss et al., 2009). Our planet's forests are a source of vast plant and animal diversity, encompassing $80 \%$ of all biomass, and tropical forests alone contain at least half of all plant and animal species on Earth (Fonseca et al., 2007). Forests play a vital role in supporting the intricate network of organisms that inhabit land and water ecosystems, including humans. It is because of the critical importance of forests that new data demonstrating rapid global deforestation is alarming (Falkner, 2013). To fully comprehend why forests are critical to all life on earth, one must first understand that our planet relies on cyclical systems of chemical and 
physical regulation to sustain life. Of these systems, the carbon cycle is of particular concern as it has experienced rapid changes due to anthropogenic activities (Schimel, 1995). The carbon cycle is a series of biochemical processes by which compounds are interconverted in the natural environment, chiefly involving the incorporation of carbon dioxide $\left(\mathrm{CO}_{2}\right)$ into living tissue by photosynthesis and its return to the atmosphere through respiration, the decay of dead organisms, and increasingly, the burning of fossil fuels (Meinshausen et al., 2014).

One of the chief activities contributing to global climate change is the destruction of forest land. In just the last three hundred years, our planet's total forest cover has been reduced by half (Fonseca et al., 2007). Rainforests once covered 14\% of the Earth's land surface (Fonseca et al., 2007). Today, rainforests cover a mere 6\%. At this rate the last remaining rainforests could be consumed in less than 40 years (Palmer \& Stephanie, 2009). Incredibly, more than 81,000 hectares of rainforest are burned everyday (De Fonseca et al., 2007). Today, Indonesia leads the world with the highest rate of deforestation (Falkner, 2013). From 2000 to 2012, Indonesia lost more than 60,000 square kilometers to logging, agriculture, and other uses (Falkner, 2013). The $\mathrm{CO}_{2}$ that is released from the burning of forest land is roughly 17\% of all global emissions (Montzka, 2015). This is more $\mathrm{CO}_{2}$ than all cars, trucks, planes, trains and ships combined emit into the atmosphere (Montzka, 2015). Forest land is destroyed or degraded in many ways, but burning is the most common (Fonseca et al., 2007). This is because traditional logging methods are financially impractical for forests comprised of non-hardwood tree species (Fonseca, et al., 2007). If we are to continue on this path of unsustainable habitat destruction, we risk disrupting the delicate balance that has taken our planet millennia to achieve.

Additionally, it is important to note that human alterations to the environment have been occurring on Earth far longer than was recently understood. "People have been affecting the global 
system through land use for not just the past 200 or 300 years, but for thousands of years" (Carson, 2015). Rapid forest loss is both damaging to the fragile atmospheric chemical balance as well as to the countless species that inhabit forest ecosystems. The current extinction rate is approximately 100 extinctions per million species a year, or 1,000 times higher than the natural background extinction rate (De Vos et al., 2015). Habitat loss (often caused by deforestation) continues to be the greatest cause of species extinction on Earth, far surpassing climate change, the exotic animal trade, hunting, invasive species, or pollution (De Vos et al., 2015).

The conversion of forest land to non-forest is consequential in another less-understood way. Darkly-colored urban structures, asphalt, and other human replacements for lighter-colored mixed forests absorb and retain more heat via a process known as the albedo effect (Fidler, 2012). Albedo is defined as the proportion of solar energy (shortwave radiation) that is reflected back into space by the Earth's surface (Meinshausen et al., 2014). Regional climatic changes have been known to occur as a consequence of the conversion of forest land, resulting in lower albedo in what is known as the 'urban heat island effect' (Fidler, 2012). This can also be true of mismanaged reforestation, especially for commercial timber lands in which dark-colored conifers have replaced mixed deciduous forests for their higher timber value (Fidler, 2012). Although, further research is needed to understand what exact role mismanaged reforestation plays in regional and global climate change (Fidler, 2012).

Deforestation, along with naturally occurring events like wildfires and volcanic events, can trigger changes in the atmosphere via the greenhouse effect. It is important to understand both what gasses contribute to the greenhouse effect and how deforestation affects their release. A greenhouse gas is defined as a gas that contributes to the greenhouse effect by absorbing infrared radiation, e.g., carbon dioxide and chlorofluorocarbons (Palmer, 2009). Other than from 
anthropogenic causes, greenhouse gasses are emitted via biomatter decay, plant respiration, natural disasters including volcanoes, forest fires, and other natural processes (Montzka et al, 2015). Although there are many greenhouse gasses of concern, $\mathrm{CO}_{2}$ is often the focus of those interested in combating climate change because all hydrocarbons inevitably break down in the atmosphere to become $\mathrm{CO}_{2}$ (Montzka et al., 2015). While it is true that the planet experiences natural fluctuations in greenhouse gas concentrations, our current levels are beyond what humanity has experienced for the last two hundred thousand years (Schmittner \& Galbraith, 2008). If we are to reverse this trend, a solution to the problem of rising $\mathrm{CO}_{2}$ levels must be developed and utilized. 


\section{Carbon Sequestration}

In this section, I will start by defining the system by which our planet regulates greenhouse gasses. Secondly, I will identify the threat of feedback loops, and the urgency required in preventing rapid changes to the Earth's atmosphere. Third, I will separate reforestation from afforestation, define both, and give rationale for the focus on reforestation instead of afforestation as a means of carbon sequestration. Furthermore, I will propose above ground carbon sequestration in rejuvenating forests as a potential solution to rising $\mathrm{CO}_{2}$ concentrations.

Carbon sequestration is the process of drawing $\mathrm{CO}_{2}$ from our atmosphere and trapping it (Palmer, 2009). Carbon sequestration is possible through plant respiration in terrestrial and aquatic ecosystems (Meinshausen et al., 2014). Forests provide nearly one third of all carbon sequestration on Earth (Schimel, 1995), but with half of all forest cover already gone (Sobrino et al., 1997), our planet's ability to reduce $\mathrm{CO}_{2}$ concentrations in the atmosphere is diminished (Meinshausen et al., 2014). Decreased forest cover compounds the problem of $\mathrm{CO}_{2}$ emissions, rendering the planet incapable of adequately responding to sudden atmospheric fluctuations (Meinshausen et al., 2014).

It is important to remember that fluctuations in Earth's atmospheric concentrations happen naturally. Many naturally occurring events release gases with varying effects on short and longterm weather phenomena. For example, sulfides, a binary compound of sulfur with another element or group, is often released in great quantities by volcanic eruptions, and has a net cooling effect on the planet (Schimel, 1995). On the other extreme, naturally occurring wildfires can release enormous amounts of $\mathrm{CO}_{2}$ into the atmosphere in a relatively short amount of time (Schimel, 1995). $\mathrm{CO}_{2}$ released by any source, including wildfires, is nearly transparent to the solar radiation emitted from the sun, but partially opaque to the thermal radiation emitted by the Earth (Schimel, 1995). Because of the difference in how CO2 transfers light radiation originating from 
the sun and reflected off of the Earth, a wildfire would have a net warming effect on the Earth's atmosphere (Schimel, 1995). Many natural phenomena other than volcanoes and wildfires contribute to changes in atmospheric gas concentrations, it is because of this that consideration for natural events must be given when calculating the role that anthropogenic sources play in observed fluctuations in the atmosphere.

Experts in the field of planetary sciences have raised alarm at the possibility of greenhouse gas-induced feedback loops beginning in the arctic and in the oceans (Azar et al., 2010). Feedback loops are vicious or virtuous circles; something that accelerates or decelerates a warming trend (Meinshausen et al., 2014). A positive feedback loop accelerates a temperature rise, whereas a negative feedback loop decelerates it (Meinshausen et al., 2014). Climate policy makers have established a goal of no more than 2-3 degrees Celsius of warming this century, arguing that any higher temperature increases could trigger devastating feedback loops impossible to reverse (Azar et al., 2010).

Forest creation initiatives, including those aimed at sequestering carbon, come in two varieties. The first variety of forest creation being reforestation; the act of establishing forest on land that had recently held tree cover (IPCC, 2000). A particular focus is given to reforestation, as it proves the most fruitful for carbon sequestration because the land has already proven viable for supporting trees. The second, rarely discussed means of forest creation is afforestation; the establishment of a forest or stand of trees in an area where there was no forest in the recent past (IPCC, 2000). Afforestation, although similar in principal to reforestation, would represent a minority opportunity for carbon sequestration. Because half of all forests have been cut since the dawn of the agricultural era, the bulk of available land for forest creation would be reforestation of recently forested lands, not afforestation (IPCC, 2000). Although afforestation would likely play 
a smaller role in any global tree planting initiative relative to reforestation, afforestation still presents an opportunity for significant carbon sequestration in predominant grassland, prairie, savannah, and other landscapes lacking complete forest cover (IPCC, 2000).

Approximately half of the tropical biome is in some form of regeneration from past human disturbance; most of which is secondary forest growing on abandoned agricultural lands and pastures (Silver et al., 2000). Reforestation of these lands, both natural and managed, has been proposed as a means to help offset increased carbon emissions to the atmosphere (Silver et al., 2000). In the tropics, a review of research data shows that aboveground biomass increases at a rate of $6.2 \mathrm{Mg} \mathrm{ha}^{-1} \mathrm{yr}^{-1}$ during the first 20 years of succession, and at a rate of $2.9 \mathrm{Mg} \mathrm{ha}^{-1} \mathrm{yr}^{-1}$ over the first 80 years of regrowth (Brown \& Lugo, 1990). During the first 20 years of regrowth, forests in wet life zones have the fastest rate of aboveground carbon accumulation with reforestation, followed by dry and moist forests (Brown \& Lugo, 1990). Soil carbon accumulates at a rate of $0.41 \mathrm{Mg} \mathrm{ha}^{-1} \mathrm{yr}^{-1}$ over a 100 -year period, but during the first 20 years it accumulates at a much faster rate of 1.30 Mg carbon $\mathrm{ha}^{-1} \mathrm{yr}^{-1}$ (Brown \& Lugo, 1990). 


\section{Scientific and Historical Evidence}

In this section, I will outline the evidence for current greenhouse gas increases compared to pre-industrialization. Second, I will identify ice cores as the primary source of historical global atmospheric condition data.

To put current greenhouse gas concentrations into perspective, one must first identify the key characteristics that make ice cores so valuable to science. Ice cores are important natural

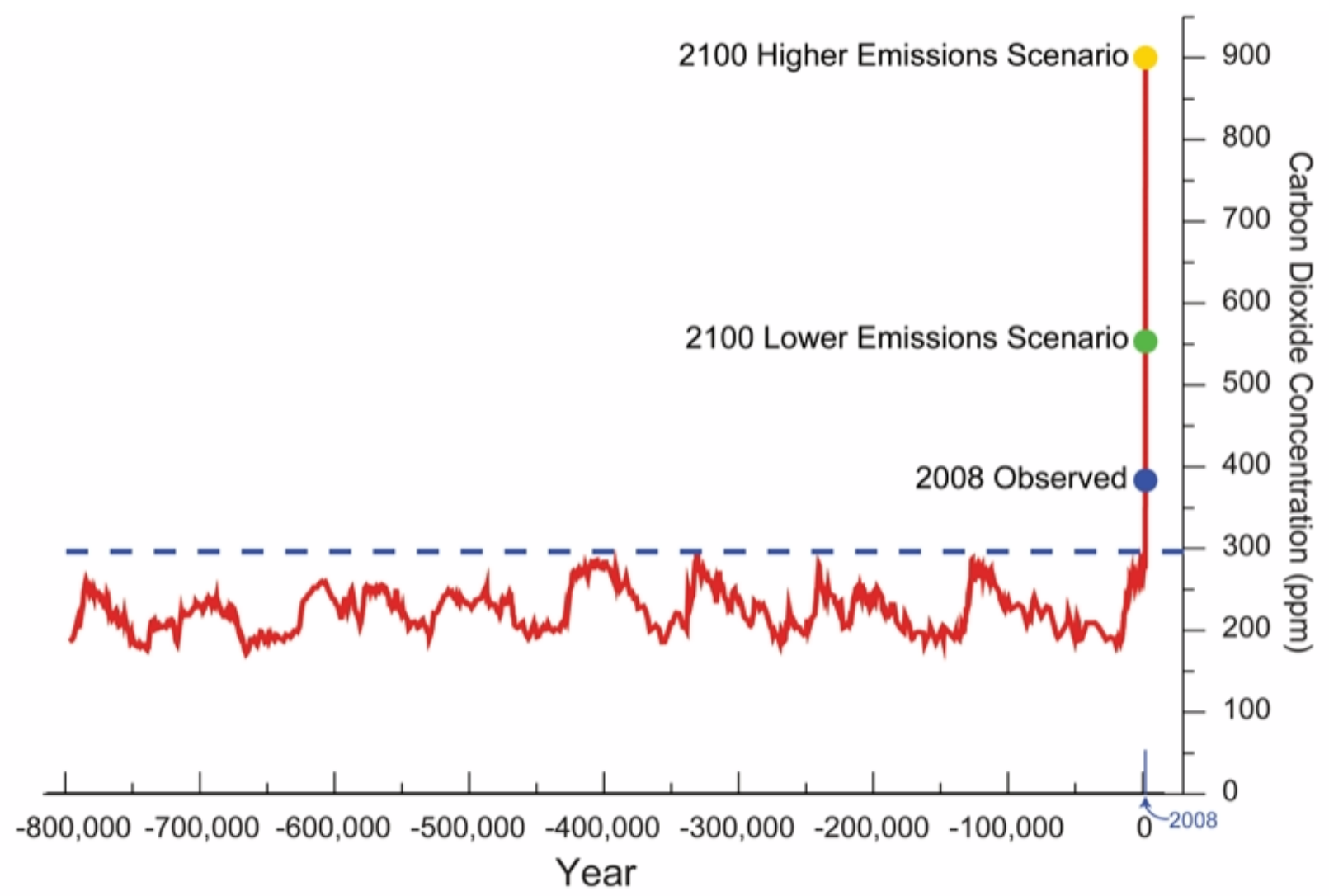

Figure 1: CO2 concentrations from the Holocene to the present (Source: NOAA, 2016)

records of the Earth's recent past. An ice core is a cylinder-shaped sample of ice drilled from a glacier (Schneider et al., 2011). Ice core records provide the most direct and detailed way to investigate past climate and atmospheric conditions (Schneider et al., 2011). Snowfall that collects on glaciers each year captures atmospheric concentrations of dust, sea-salts, ash, gas bubbles, and human created industrial pollutants (Schneider et al., 2011). Analysis of physical and chemical 
properties of an ice core can reveal past variations in climate dating back hundreds of thousands of years (Schneider et al., 2011). Ice core records can be used to reconstruct temperature, atmospheric circulation strength, precipitation, ocean volume, atmospheric particulates, volcanic eruptions, solar variability, marine biological productivity, sea ice extent, and forest fires (Schneider et al., 2011). Paleoclimatology (the study of past climates) relies heavily on information gathered from ice cores (NOAA, 2016). Previous mechanisms for identifying past climatic periods utilized dendrochronology (tree ring counting), sedimentology (the study of sediment), coral layers, and other low resolution methods (NOAA, 2016). Like dendrochronology, ice core paleoclimatology has proven to be an accurate record of many atmospheric variables. Ice core samples from the Antarctic show that pre-industrialization $\mathrm{CO}_{2}$ levels were 260-270 parts per million (ppm) (Wigley, 1983). With current $\mathrm{CO}_{2}$ concentrations at a record high of $402.26 \mathrm{ppm}$ (NOAA, 2016), the question remains; could reforestation alone reduce $\mathrm{CO}_{2}$ concentrations to preindustrial levels? The purpose of this paper is to answer this academic question in a manner that is objective and constructive. 


\section{Methodology}

First, current and pre-industrialization $\mathrm{CO}_{2}$ concentrations were established using the January 2016 paleoclimatology data from the National Oceanic and Atmospheric Administration collected by their Earth System Research Laboratory (NOAA, 2016). Parts per million $\mathrm{CO}_{2}$ concentrations were reconstructed from Antarctic ice core samples revealing a paleo-climatic history of the previous 800,000 years (Figure 1: NOAA, 2008).

Second, future $\mathrm{CO}_{2}$ concentration to 2050 were projected using land use, energy production, and transportation trends (OECD Environmental Outlook, 2012). The $2050 \mathrm{CO}_{2}$ concentration projection was calculated with current trends and without intervention and is supported by multiple literary sources (NOAA, 2008).

Third, present global forest cover was acquired from tree-density counts of 430,000 hectares and remote imaging (Crowther et al., 2015). Total available land for reforestation was calculated using International Panel on Climate Change (IPCC) satellite data for boreal, temperate, and tropical forests (IPCC, 2000). Afforestation and reforestation potential was considered using available land data for the 55-year period beginning in 1995 and ending in 2050 (IPCC, 2000).

Finally, I found supporting literature for total carbon sequestration potential from reforestation in boreal, temperate, and tropical environments and subtracted this sequestration potential from the projected $2050 \mathrm{CO}_{2}$ concentrations. Lastly, I compared the $2050 \mathrm{CO}_{2}$ projection with the uptake from global reforestation to pre-industrial $\mathrm{CO}_{2}$ concentrations. 


\section{Results}

Sources from the literature show that pre-industrial $\mathrm{CO}_{2}$ concentrations in the atmosphere were between 260-270 ppm (Wigley, 1983) (NOAA, 2008). The current atmospheric $\mathrm{CO}_{2}$ concentration is 402.26 ppm (NOAA, 2016). The future $\mathrm{CO}_{2}$ concentration without intervention is projected to be 685 ppm by 2050 (OECD Environmental Outlook, 2012) (NOAA, 2008). The conversion factor for $\mathrm{CO}_{2}$ in the atmosphere to carbon on Earth was found to be $1 \mathrm{ppm} \mathrm{CO}_{2}$ equals 2.12 gigatons carbon (IPCC). For total $\mathrm{CO}_{2}$ concentration in the atmosphere to return to preindustrial levels, I calculated that 290 gigtaons carbon would need to be removed.

The most recent global tree survey demonstrates that total global tree count was measured at roughly 3 trillion individuals, a 46\% decrease from the onset of agriculture 12,000 years ago (Crowther et al., 2015). Total carbon sequestration potential was calculated to be $60-87$ gigatons (Gt C) (Sohngen, 2002). Current average distribution of carbon sequestration globally from naturally occurring terrestrial sources was found to be $5 \%$ in boreal forests, $70 \%$ in tropical forests, and $25 \%$ in temperate forests (Brown et al., 1996). The literature on tree science suggests that a global reforestation initiative aimed at reducing $\mathrm{CO}_{2}$ concentrations would need to be focused in tropical forests, as they hold $70 \%$ of $\mathrm{CO}_{2}$ sequestration potential globally (Brown et al., 1996). Mixed species forests were found to be the most productive regarding $\mathrm{CO}_{2}$ sequestration (Sohngen, 2002). Based on the evidence, I suggest that any reforestation effort to combat rising $\mathrm{CO}_{2}$ concentrations will need to be region specific and offer an array of native tree species.

Finally, a global reforestation initiative that began reforesting all available lands in 2016 would equate to an increase of $2 \%$ annual uptake from naturally occurring sequestration levels (IPCC, 2016). I have calculated that a $2 \%$ annual uptake in $\mathrm{CO}_{2}$ from current levels holds the 
potential to result in an increase in carbon sequestration of $60-87 \mathrm{Gt} \mathrm{C}$ by 2050 , which would provide a 2050 atmospheric $\mathrm{CO}_{2}$ equivalent of 373.96-361.22 (ppm). 


\section{Discussion}

In this section I will discuss the significance of my findings. Contemporary academic discussion regarding greenhouse gas concentrations focus heavily on the production and release of $\mathrm{CO}_{2}$ and methane by humans, but rarely on the means of sequestration. Carbon sequestration, a natural process by which the planet traps the greenhouse gas in organic material here on Earth via photosynthesis, has been proposed as a partial solution to growing $\mathrm{CO}_{2}$ concentrations. However, rarely has the idea of mass reforestation for means of carbon sequestration been seriously considered among either the scientific or political community.

The lack of interest in widespread reforestation is likely due to the complex nature of the physical sciences and the common misconceptions around both climate change and forest science. Researchers, tasked with studying the causes and effects of climate change are limited in their studies by financial means and political interest. Rarely are scientists funded to study the positive effects of re-growing forests. Sadly, this disinterest in the critical role that forests play in the carbon cycle and the potential role they could play in a solution to climate change has gone largely ignored.

Recognizing the need for analysis of reforestation regarding climate change, I chose to focus on three aspects of reforestation that I believed to be missing. First, I knew that any attempt to decrease $\mathrm{CO}_{2}$ concentrations would require a reference point by which current $\mathrm{CO}_{2}$ concentrations could be compared. This reference point could have been many dates, since we now have access to ice core data dating back hundreds of thousands of years. It would have been interesting to compare $\mathrm{CO}_{2}$ concentrations to 1950 , as that was a crucial time in both American and international development, or the year 2000 to show the dramatic change that has occurred in the atmosphere since the turn of the millennium. Instead, I chose to compare current $\mathrm{CO}_{2}$ 
concentrations to 1750; the well-recognized beginning of the industrialized era (Wigley, 1983). Although imperfect, comparing the current state of $\mathrm{CO}_{2}$ in the atmosphere to 1750 provided an effective basis for beginning my research.

The second aspect of my focus was to determine the amount of available land that could potentially be reforested. Determining land suitable for reforestation is not as simple as calculating all land that was once forest that is no longer, because much of this land is now replaced with human habitation, industrial production, or agriculture. Instead, counting available land for reforestation requires a patient analysis of all global agricultural lands that have been abandoned and left to fallow, once logged lands that were never replanted, grasslands that could support forest, and other currently vacant areas suitable for forest. Thankfully, researchers from the International Panel on Climate Change have compiled this data. I was able to draw upon their satellite data and land surveys to confirm the total amount of land available for reforestation globally.

Lastly, the final aspect of reforestation that I focused on was the carbon sequestration potential that these reforest-able lands hold. I found that carbon sequestration potential in these vacant lands amounted to only 60-87 gigatons (Gt C) (Brown et al., 1996). Additionally, I found that the distribution of carbon potential was lopsided in favor of tropical forests, with a distribution resulting in the following: $5 \%$ in boreal forests, $70 \%$ in tropical forests, and $25 \%$ in temperate forests (Brown et al., 1996). This is due to dramatic differences in net primary production (NPP) that results in tropical forests providing more carbon capture efficiency, hectare-for-hectare, than in any other terrestrial biome (Brown et al., 1996). I used this carbon sequestration potential of 60$87 \mathrm{Gt} \mathrm{C}$ to calculate an equivalent ppm in the atmosphere after 50 years of increased carbon uptake. My findings; a potential reduction of $7.57-11.36 \%$ is far short of the $51.8 \%$ reduction necessary to bring $\mathrm{CO}_{2}$ concentrations back to preindustrial levels. This invites the question, would a global 
reforestation campaign be worth it? Although less than the 51.8\% reduction desired, it would be a step in the right direction and a key piece of the puzzle to combatting climate change. 


\section{Limitations}

In this section, I will briefly analyze the breadth of the literature available regarding the subjects discussed in this paper. I will list the common fields of study for the authors cited, any potential biases, their chronological significance, and other relevant information drawn from my sources.

Of the twenty-eight sources that I utilized to support my research, I chose to annotate the thirteen most influential. All twenty-nine publications cited are peer reviewed. The authors are all currently employed as researchers and many hold current positions as professors. Once I established my research question, I chose to limit my search of sources to those published in the last two decades. I chose to cite recent publications because of their relevance and common digital accessibility. Although I prioritized recent publications, I chose to cite Wrigley et al., 1983 because of the depth of research that the authors conducted regarding ice core analysis. Wrigley et al., 1983 perfectly articulates the methodology required to extract information from ice cores in a way that more recent publications on the subject do not.

While searching for sources to answer my research question, I chose only to cite publications from authors who stated no existential bias or conflict of interest. It is critically important that scientists conduct independent research that is free from the constraints of financial interests. In our recent political era, the topic of climate change is widely debated as many critics outside of the world of academia question the financial biases of climate researchers. To support my writing, I chose to eliminate any research that was conducted by anyone with a clear conflict of interest.

A noteworthy theme throughout the sources cited is an emphasis on future predictions. Although any predictions made by the researchers are rooted in historical evidence, the tendency 
is to conclude with a prediction for the future. From future forest cover to $\mathrm{CO}_{2}$ concentrations, predictions by the researchers draw attention to their work, stir additional discussion, and may draw recognition for the researchers. However, this can be problematic as some researchers may feel pressure to draw unnecessary conclusions about past phenomena and project those findings into the future. It is important to consider the variability of the natural world and the poor history that humans have at accurately predicting the future.

Any academic writing requires the use of citations to both support the legitimacy of the findings and provide a path for any future reader to check the accuracy of the information cited. I have intentionally crafted my bibliography to reflect the wide array of related literature I drew upon in my writing. My bibliography is as follows: thirteen sources with annotations, and fifteen additional sources without annotations. 


\section{Conclusion}

As the planet continues to change along with the growing human population, it is more necessary than ever to cultivate healthy forest ecosystems that offset the release of carbon dioxide from anthropogenic sources. Because of the rapid nature of human expansion, it is imperative to not only end the widespread practice of deforestation, but also to begin reforesting all available lands. Initially, I sought to answer the question of whether or not reforestation alone could reduce $\mathrm{CO}_{2}$ concentrations to pre-industrial levels. Previous studies have found that available land for reforestation in temperate and tropical regions provide an opportunity for an annual $2 \%$ average uptake in global $\mathrm{CO}_{2}$ sequestration (Brown et al., 1996). This increase would translate into a projected $2050 \mathrm{CO}_{2}$ concentration of 361.22-373.96 parts per million (ppm). This reduction, although significant, would only represent a $7.57-11.36 \%$ reduction, far short of the $51.8 \%$ reduction necessary to bring $\mathrm{CO}_{2}$ concentrations back to preindustrial levels.

With an understanding of the degree to which global reforestation would affect future $\mathrm{CO}_{2}$ concentrations, it is now possible to say that no, a global effort to reforest all available lands would not go far enough as to bring atmospheric concentrations back below pre-industrial levels. Although disconcerting to some, the evidence that atmospheric $\mathrm{CO}_{2} \mathrm{ppm}$ concentrations could be reduced by $7.57-11.36 \%$ simply via a natural, and relatively safe means like reforestation should suggest that the greater goal is still possible, although we hold no single solution. 


\section{Bibliography}

\section{Source 1:}

Carson, J., Whitney, B., Mayle, F., Iriarte, J., Prumers, H., Soto, J., \& Watling, J. (2014).

Environmental Impact of Geometric Earthwork Construction in Pre-Columbian Amazonia. Proceedings of the National Academy of Sciences, 10497-10502.

This research paper is intended for climatologists and anthropologists. John Francis Carson is a post-doctorate researcher at the University of Reading in the United Kingdom and his six coauthors have all written on the subject of anthropology. Their work, released in 2014 is extremely relevant to current discussions regarding setting goals for greenhouse gas reductions. The authors cite no conflict of interest. Their theoretical framework includes the paradigm shift that the Amazon rainforest observed by European explorers was not in fact a virgin forest, but an altered landscape much like others found around the planet. Their question was how much did prehistoric people alter the landscape of the Amazon before the arrival of Europeans? Their ultimate finding was that "people have been affecting the global climate system through land use for not just the past 200 or 300 years, but for thousands of years." Their methods included the dating of humanmade structures beneath the Amazon rainforest, built upon open grassland, but since covered by thick forest. My reaction to this research is one of little surprise. It is well established that humanity's impact on planet Earth has been long and far reaching. It only makes sense that native peoples with early agriculture and advanced settlement building were able to clear the forest for their civilizations and that the evidence of such structures would be exposed by contemporary deforestation. 


\section{Source 2:}

Meinshausen, M., Smith, S., Calvin, K., Daniel, J., Kainuma, M., Lamarque, J., . . Vuuren, D. (2011). The RCP greenhouse gas concentrations and their extensions from 1765 to 2300. Climatic Change, 213-241.

This article published in the journal of Climate Change is intended for climatologists and environmental scientists. Professor Meinshausen is an Earth System Analysist for the Potsdam Institute for Climate Impact Research (PIK) in Potsdam Germany. Meinshausen and the other authors all study climate change and have written about Earth's cyclical systems. Their work from 2011 is certainly relevant and necessary in the international conversation about capping greenhouse gas emissions using evidence for past $\mathrm{CO} 2$ concentrations and projections for $\mathrm{CO} 2$ concentrations until 2300. Their methods include the projecting of current emissions trends and considering the $\mathrm{CO} 2$ breakdown rate in the atmosphere. Using this information the authors were able to project a range of $1.5 \mathrm{C}$ to $4.5 \mathrm{C}$ of warming between now and 2100 . The researchers acknowledged no conflict of interest. My reaction is that of skepticism because of the nature of predictions like this one that are nearly one-hundred years into the future. The most useful information from their work is the determining of past $\mathrm{CO} 2$ concentrations from ice cores, not the future predictions. Predictions into the future can always be difficult to produce with accuracy. I am especially wary of any prediction hundreds of years in advance.

\section{Source 3:}

Schimel, D. S. (1995), Terrestrial ecosystems and the carbon cycle. Global Change Biology, 1: 77-91. doi:10.1111/j.1365-2486.1995.tb00008.x 
This journal article is intended for biologists and climatologists. This article form 1995 was one of the first of its kind to compare atmospheric gradients of $\mathrm{CO} 2$ to determine the role that terrestrial carbon sinks play in the global carbon cycle. The author David Schimel is an expert in remote sensing and works studying climatology at the National Ecological Observatory in Boulder. Although his work on the subject in now twenty years old, his findings are absolutely relevant to current attempts at reforestation as a means to fight global climate change. Schimel attempted to detail beyond the IPCC assessment on procedures used to approximate the flux uncertainties of the global climate cycle. His method was to compare atmospheric gradients of $\mathrm{CO} 2$ to determine the location of terrestrial carbon 'sinks' and value the share of carbon they are capable of sequestering. His finding was that there is "increasingly strong evidence for terrestrial sinks, potentially distributed between the Northern Hemisphere and tropical regions, but conclusive detection in direct biomass and soil measurements remain elusive." The author does not acknowledge any conflict of interest. Because I have studied this issue in the past, I was already familiar with the $1 / 3^{\text {rd }}$ estimate for terrestrial carbon sinks relative to ocean sequestration capability.

\section{Source 4:}

Schmittner, A., \& Galbraith, E. (2008). Glacial greenhouse-gas fluctuations controlled by ocean circulation changes. Nature, 373-376.

This article in the journal of Nature is intended for climatologists and the article's two authors come from the college of Oceanic and Atmospheric sciences Oregon State and Princeton 
University. Their work, published in 2008 is relevant to the international discussion on atmospheric greenhouse gas concentrations. The author's question involves the relationship between historical land-carbon inventories and fluxuations in atmospheric $\mathrm{CO} 2$ concentrations. Their methods included presenting simulations of glacial climate biogeochemical cycles compared to the atmospheric $\mathrm{CO} 2$ record. Their findings were that despite significant changes in the land carbon inventory, $\mathrm{CO} 2$ variations on millennial timescales are dominated by slow changes in the deep ocean inventory of biologically sequestered carbon and are correlated with Antarctic temperature and Southern Ocean stratification. Concluding that Ocean circulation is the primary mechanism for glacial $\mathrm{CO} 2$ and NO2 fluxuations on millennial timescales. The authors did not acknowledge a conflict of interest. My reaction is similar to the previous source because it is well established that most of the natural sequestration that happens annually occurs in the oceans.

\section{Source 5:}

Sobrino, C., Ramil-Rego, P., \& Guitin, M. (1997). Upland vegetation in the north-west Iberian Peninsula after the last glaciation: Forest history and deforestation dynamics. Vegetation History and Archaeobotany Veget Hist Archaebot, 6(4), 215-233.

This article in the journal of Vegetation History and Archaeobotany is intended for students and academics in the field of climatology. The three authors are all three professors in Spain. Their field of expertise include pollen analysis, late-glacial changes and the Holocene. Their work, although nearly twenty years old is still relevant to finding solutions and understanding the current deforestation dynamic present in temperate forests. The author's theoretical framework includes the notion that pollen samples can allow for extrapolation into sequencing of the main stages of 
vegetation dynamics from the late-glacial until the present. Their method was to present the results from a pollen analysis of the north-west Iberian Peninsula in a mountainous area. The pollen diagrams, corresponding to seven dates, document the coming of cryophilous forests. Their major finding was that these mixed deciduous forests dominated the landscape, and suddenly vanished around 3,000 years ago as a result of increased farming activity. The results are compared to other mountainous areas in the northern Iberian Peninsula and southern France. The authors did not acknowledge any conflict of interest. I am somewhat surprised by this finding. I would have expected rapid deforestation to have occurred much more recently than 3,000 years ago.

\section{Source 6:}

Azar, C., Lindgren, K., Obersteiner, M., Riahi, K., Vuuren, D., K. Michel G. J. Den Elzen, . . Larson, E. (2010). The feasibility of low CO2 concentration targets and the role of bioenergy with carbon capture and storage (BECCS). Climatic Change, 100(1), 195-202.

This article in the journal of Climate Change in intended for public policy makers. Three of the authors work in university research applied systems analysis and the other two work from the Environmental Assessment Agency working in Austria and the Netherlands. Their work on carbon capture and storage from 2010 is especially pertinent to my writing about forest potential for carbon sequestration. They come from a theoretical framework of negative emissions technologies, promising to sequester carbon while producing energy, a process that is still largely theoretical. Their question was whether or not diversified energy portfolios could attain stabilization of atmospheric greenhouse gas concentrations at a level that "would prevent dangerous anthropogenic interference with the climate system." They went about this by analyzing 
the carbon outputs of various energy portfolios and ultimately found that negative emissions technologies like biomass energies and carbon capture would significantly enhance the possibility of meeting low concentration targets (at or around 350ppm CO2). The authors did not acknowledge any conflict of interest. My first reaction was that they did not consider the planet's decreasing ability to sequester carbon naturally while considering national energy portfolios.

\section{Source 7:}

Sohngen, B., \& Mendelsohn, R. (2002). An Optimal Control Model of Forest Carbon Sequestration. American Journal of Agricultural Economics, 85(2), 448-457.

This scientific study in the Oxford Journal of Agricultural Economics is intended for land owners and policy makers. The authors, Brent Sohngen and Robert Mendelsohn are both professors and experts on carbon sequestration and energy abatement. Their theoretical framework is that forest sequestration accounts for one-third of total carbon abatement, with tropical forests storing two-thirds of this added carbon. Their question was whether or not an increasing "carbon rental price" over time would successfully reduce greenhouse gas concentrations akin to a carbon trading system. Their findings were that carbon sequestration is costly but that "landowners can sequester substantial amounts of carbon in forests mainly by increasing forestland and lengthening field rotations." The authors did not acknowledge any conflicts of interest. I was not surprised by these findings. They simply support the argument that increases in forest cover is both the most effective way of sequestering carbon and also the cheapest. 


\section{Source 8:}

Cole, C., Duxbury, J., \& Freney, J. (1997). Global estimates of potential mitigation of greenhouse gas emissions by agriculture. Nutrient Cycling in Agroecosystems, 49(1-3). Doi:10.1023/A:1009731711346

This journal article is intended for public policy makers. The authors, Cole et al. are all international researchers working on the issue of greenhouse gas emission mitigation. Their theoretical framework is that agriculture is capable is significantly reducing greenhouse gas emissions. Their question was, what is the most significant potential source of greenhouse gas reduction in the agriculture industry? Their findings were that there is a $42 \%$ possible reduction in carbon offsets by biofuel production, $32 \%$ could result in direct reductions in $\mathrm{CO} 2$ emissions, $16 \%$ from reduced $\mathrm{CH} 4,15 \%$ from a more efficient use of cropland, and $10 \%$ from reduced emissions of N2O. The authors did not acknowledge any conflicts of interest. My reaction is that maximizing cropland efficiency alone will never bring global greenhouse gas concentrations back down below pre-industrialization levels. However, converting the land to forest likely could.

\section{Source 9:}

Zomer, R., Trabucco, A., Bossio, D., \& Verchot, L. (2008). Climate change mitigation: A spatial analysis of global land suitability for clean development mechanism afforestation and reforestation. Agriculture, Ecosystems \& Environment, 126(1-2), 67-80.

This article in the journal of Agriculture, Ecosystems and Environment is intended for an audience of global policy makers and other academics in the field of sustainable development. The 
authors, Zomer et al. are a mixture of agricultural and climate change researchers whose theoretical framework comes from the greenhouse gas emission targets of the Kyoto protocol; allowing for a small percentage of emission reduction to come from afforestation and reforestation. Their question was, what is the amount of total global land suitable for reforestation? Their finding was that 749Mha of land is biophysically suitable for meeting the CDM-AR eligibility criteria for reforestation. My reaction is that this is a vast area with enormous potential, especially when one considers that the researchers excluded marginal lands in arid environments.

\section{Source 10:}

Houghton, R. A.. (1990). The Future Role of Tropical Forests in Affecting the Carbon Dioxide Concentration of the Atmosphere. Ambio, 19(4), 204-209. Retrieved from http://www.jstor.org/stable/4313693

This article, published in the journal Ambio is intended for academics in the Royal Swedish Academy of Sciences. The author, Richard Houghton, is an expert on carbon dioxide and the runaway greenhouse effect. His work on reforestation potential is relevant today. However, the publication date of 1990 means that much of his knowledge about sustainable energies and new technological potential was limited to the time in which it was written. His theoretical framework is that "Tropical deforestation has been responsible, in part, for the increasing concentrations of $\mathrm{CO} 2$ in the atmosphere. In 1980, the amount of carbon released to the atmosphere (as CO2) from deforestation was 10 to $50 \%$ of the annual emission from fossil fuels. If current trends continue until tropical forests are eliminated, about as much carbon will be released to the atmosphere in the next 50 to 100 years as has been emitted from worldwide combustion of fossil fuels since the 
start of the industrial revolution." His question is ultimately whether or not a reversal of tropical deforestation and subsequent reforestation could withdraw as much carbon from the atmosphere as if current deforestation rates continued unabated. His major finding was that "If the halting of deforestation is accompanied by the substitution of sustainably harvested wood fuels for fossil fuels and if use of fossil fuels does not increase above current rates, the total net release of carbon to the atmosphere from both fossil fuels and deforestation could be eliminated indefinitely." The author did not acknowledge any conflicts of interests. My reaction is that this source more than any others proves the need to expand reforestation to sequester carbon and offset previous deforestation and fossil fuel emissions.

\section{Source 11:}

Da Fonseca GAB, Rodriguez CM, Midgley G, Busch J, Hannah L, Mittermeier RA (2007) No Forest Left Behind. PLoS Biol 5(8): e216. doi:10.1371/journal.pbio.0050216

This research article is intended for conservationists and biologists. Da Fonseca et al., study biology and have written extensively about conservation efforts. Their work regarding projected increases in global $\mathrm{CO} 2$ concentrations due to tropical deforestation is especially pertinent today, and certainly relevant to my thesis question. The theoretical framework of the article focuses on research that suggests CO2 concentrations will rise between 29-129ppm over the next century. The question of the article is whether or not a carbon trading system could work to reduce deforestation in tropical countries the same way that carbon trading programs have proven to reduce emissions in developed nations. Their findings were that a reward system for reduced deforestation or reforestation would likely lead to the transfer or "leaking" of deforestation to 
neighboring countries. The authors do not acknowledge any conflicts of interest. My reaction to this article is mixed. Alternatively, it is possible that rewards for countries with a high percentage of remaining forest and a low rate of deforestation could spill existing deforestation into neighboring countries that do not qualify for such rewards. However, it is also possible that a reward system could accompany a similar fund for preserving land and providing alternative occupations for people in nations with high deforestation rates.

\section{Source 12:}

Wigley, T. (1983). The pre-industrial carbon dioxide level. Climatic Change, 5(4), 315-320. doi:10.1007/BF00140798

This research of Antarctic ice cores by Wigley and published in the journal of Climate Change is critical for understanding the change that has occurred in the Earth's atmosphere since the industrial revolution. The purpose of the research was to establish the $\mathrm{CO} 2$ concentration in the atmosphere pre-industrialization. Before this research, it was commonly believed that the preindustrial CO2 concentration was 290ppm. However, the findings of the researcher was that preindustrial levels sustained at 260-270ppm, significantly below previous estimates. This is in comparison to a $\mathrm{CO} 2$ concentration exceeding 400ppm today. My reaction to the research is that even a "pre-industrial CO2 concentration" of 260-270ppm is likely higher than would have occurred otherwise. Without human land use changes, forest cover would have extended far beyond what existed for the past several thousand years as established by Sobrino et al. (1997) in their article; Upland vegetation in the north-west Iberian Peninsula after the last glaciation: Forest history and deforestation dynamics. 


\section{Source 13:}

Palmer, Charles; Engel, Stefanie (2009). Avoided Deforestation: Prospects for Mitigating Climate Change. Retrieved from http://www.eblib.com

This book, authored by Charles Palmer and Stefanie Engel is relevant because it discusses the issue of avoided deforestation as a means of fighting climate change. Their work, published in 2009 and citing heavily from previous studies in the 2000's, is specific in its quest to evaluate the science behind claims that forests may hold the key to preventing disastrous climate change. The authors look at previous studies into carbon sinks in tropical biomes and their potential to sequester carbon or release it depending on their protection or destruction. Their findings, suggest that any carbon offset programs may not have the intended consequences because policy makers do not always have accurate information about the science behind carbon sinks. For instance, some lands hold far more carbon stored in them than other land, but a blanket policy on preventing deforestation does not recognize the inherent value that these lands hold over others and could lead to deforestation on land far more important for conservation.

\section{Additional sources:}

Allen JC, Barnes DF. 1985. The causes of deforestation in developing countries. Annals of the Association of American Geographers 75: 163-184.

Amelung T, Diehl M. 1992. Deforestation of Tropical Rain Forests: Economic Causes and Impact on Development. Tübingen (Germany): J. C. B. Mohr. 
Angelsen, A., \& Kaimowitz, D. (Eds.). (2001). Agricultural Technologies and Tropical Deforestation. Wallingford, Oxon, GBR: CABI Publishing. Retrieved from http://www.ebrary.com

Bawa KS, Dayanandan S. 1997. Socioeconomic factors and tropical deforestation. Nature 386: 562-563. Bilsborrow RE. 1994. Population, development and deforestation: Some recent evidence. Pages 117-134 in United Nations, Department of Economic and Social Information and Policy Analysis, ed. Population, Environment, and Development. New York: United Nations Press.

Carbon dioxide concentration | NASA Global Climate Change. (2016, April 24). Retrieved April 25, 2016, from http://climate.nasa.gov/vital-signs/carbon-dioxide/

Geist, H., \& Lambin, E. (n.d.). Proximate Causes and Underlying Driving Forces of Tropical Deforestation. Bioscience, 143-143.

Greenhouse gas concentrations continue climbing | WMO. (n.d.). Retrieved April 25, 2016, from https://www.wmo.int/pages/mediacentre/press_releases/pr_934_en.html

Land Use, Land-Use Change and Forestry. (n.d.). Retrieved April 25, 2016, from http://www.ipcc.ch/ipccreports/sres/land_use/index.php?idp=151 
NOAA ESRL Global Monitoring Division. (2016, April 5). Retrieved April 25, 2016, from http://www.esrl.noaa.gov/gmd/

Osazuwa-Peters, Oyomoare L., et al. "Selective logging: Do rates of forest turnover in stems, species composition and functional traits decrease with time since disturbance? - A 45year perspective." Forest Ecology and Management 357 (2015): 10+. Global Reference on the Environment, Energy, and Natural Resources. Web. 2 Nov. 2015.

Sauer, Carl Ortwin. 1958. "Man in the Ecology of Tropical America.” In Land and Life: A Selection from the Writings of Carl Ortwin Sauer, ed. John Leighly. Berkeley: University of California Press.

Silver, W. L., Ostertag, R., \& Lugo, A. E. (2000). The Potential for Carbon Sequestration Through Reforestation of Abandoned Tropical Agricultural and Pasture Lands. Restor Ecology Restoration Ecology, 8(4), 394-407. doi:10.1046/j.1526-100x.2000.80054.x

Struhsaker, Thomas T. 1998. "A Biologist's Perspective on the Role of Sustainable Harvest in Conservation.” Conservation Biology12(4): 930-932.

Wolvekamp, Paul, ed. 1999. Forests for the Future: Local Strategies for Forest Protection, Economic Welfare, and Social Justice. London: Zed Books. 
Wunder, S. (2000). Economics of Deforestation : The Example of Ecuador. New York, NY, USA: Palgrave Macmillan. Retrieved from http://www.ebrary.com 